\title{
INTRAOPERATIVE PARATHYROID HORMONE MONITORING DURING PARATHYROIDECTOMY: DESCRIPTION OF OUR CLINICAL EXPERIENCE.
}

Tomé $M^{1}$, Martínez de Pinillos $G^{2}$, Méndez $M^{2}$, Cuéllar $E A^{2}$, García $F$, Fernández-López $P$, Fernández-Peña $P$, García de Quirós JMP, Hidalgo $\mathcal{R}^{\mathcal{R}}$, Rivas $\mathcal{M}^{\mathcal{R}}$, Durán $\mathcal{S}^{2}$, Cózar $\mathrm{MV}^{\mathcal{R}}$.

2

European Society

of Endocrinology
1. Endocrinology and Nutrition. Hospital Punta de Europa. Algeciras. SPAIN.

2.Endocrinology and Nutrition . Valme Universitary Hospital. Sevilla. SPAIN

\section{INTRODUCTION}

* Primary hyperparathyroidism is caused by a single adenoma in $85 \%$ of cases. This is why bilateral neck exploration seems to be a very aggressive procedure in a large number of cases. Intraoperative parathyroid hormone (IOPTH) monitoring could be a useful tool in primary hyperparathyroidism surgery allowing a less invasive surgical approach. The aim of our study is to evaluate the possible impact of the measurement of IOPTH during surgery.

\section{METHODS}

* Retrospective study in which we included all patients who underwent parathyroidectomy with IOPTH monitoring between 2008 and 2013. We considered the following variables:

* Preoperative localization techniques.

* Neck exploration (uni or bilateral).

* Prediction of curative parathyroid resection by using MIAMI criteria (>50\% drop from highest baseline IOPTH level at 10

minutes after excision)

* Cure (normal calcemia 6 months after surgery).

* Subsequently, we compared this sample with a group of patients who underwent parathyroidectomy between 2000 and 2002 without IOPTH monitoring.
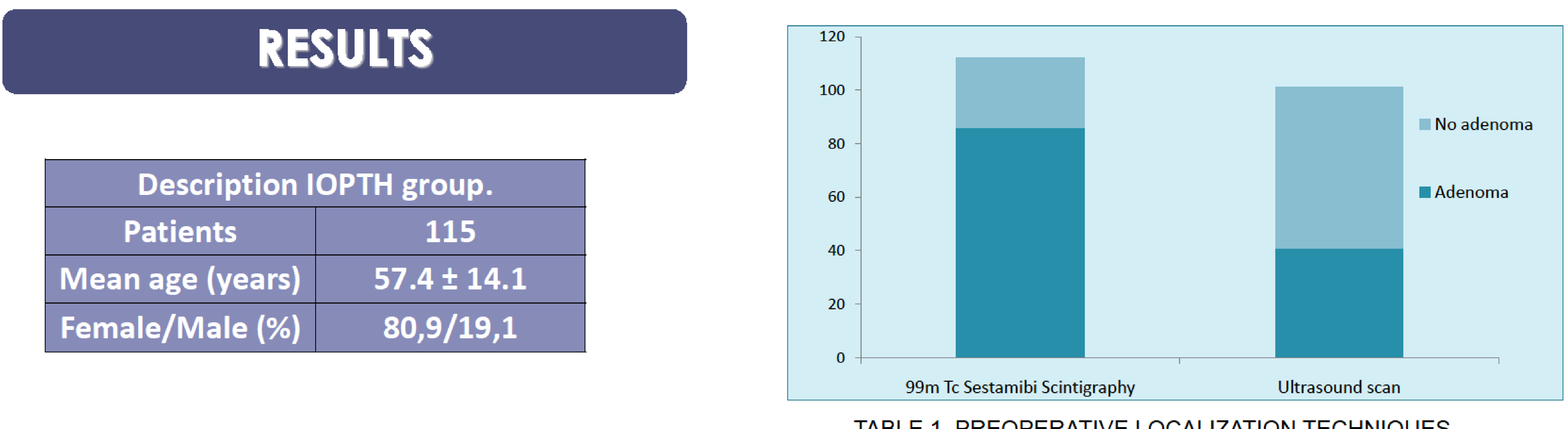

\section{-99mTc Sestamibi Scintigrahphy $97,4 \%$ (76,8\% adenoma) \\ -Ultrasound $87,8 \%$ \\ (40,6\% adenoma)}

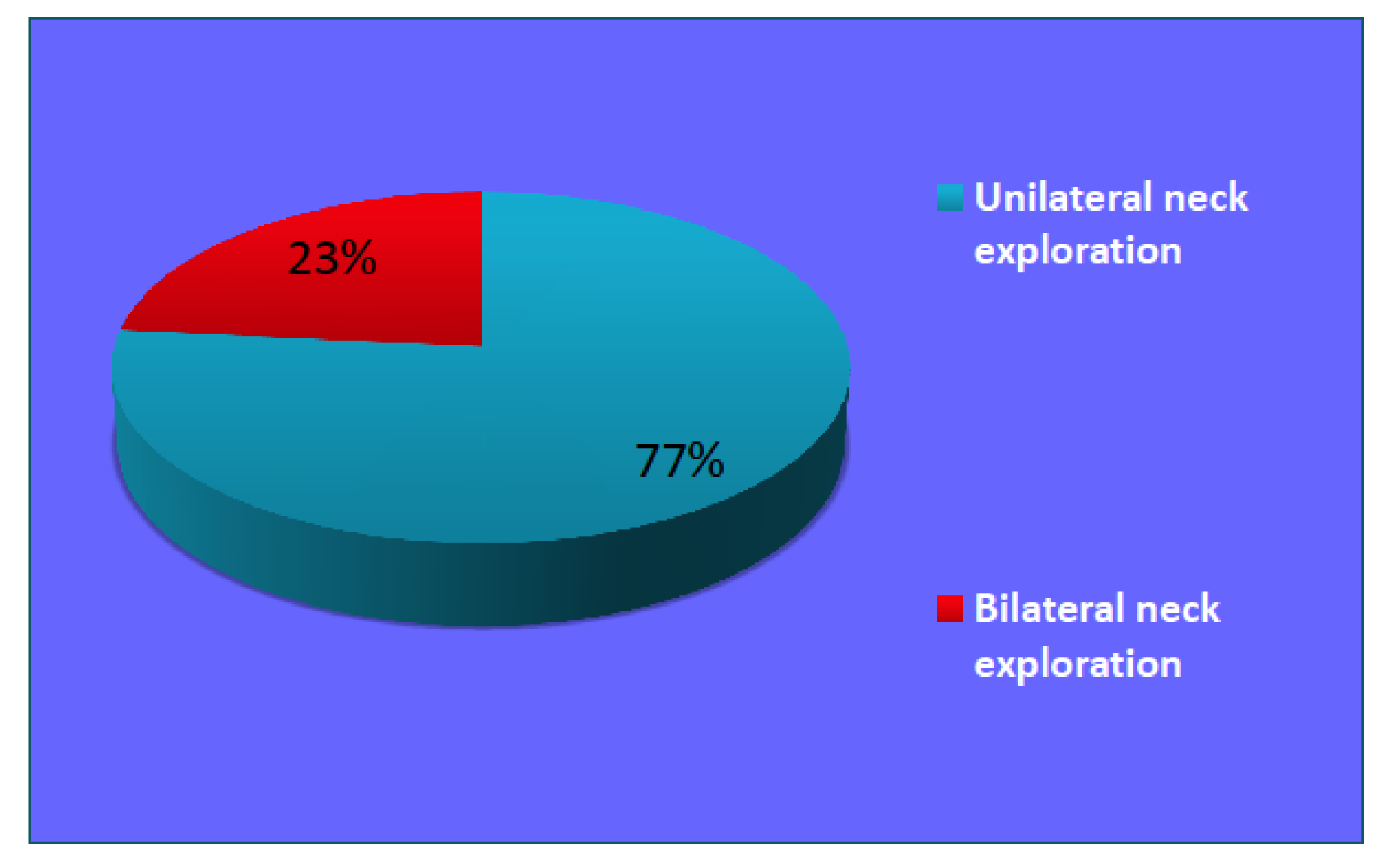

TABLE 2. NECK EXPLORATION

- Unilateral neck
exploration: $100 \%$
cure.
-Bilateral neck
exploration: $74 \%$ cure
$(p<0-0005)$

\section{exploration: $74 \%$ cure}

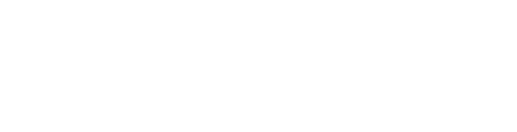

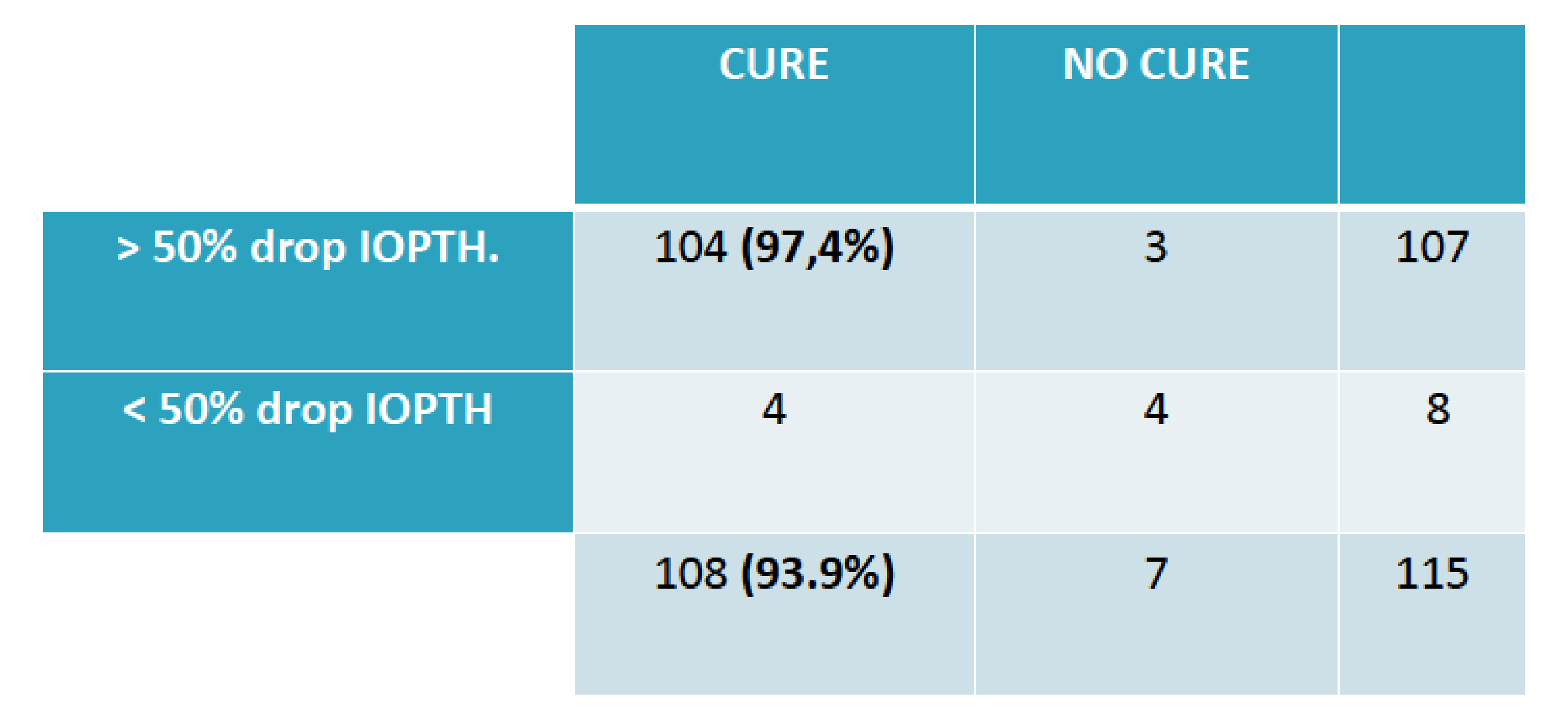

TABLE 3. PREDICTION OF CURATIVE PARATHYROID RESECTION BY USING MIAMI CRITERIA.

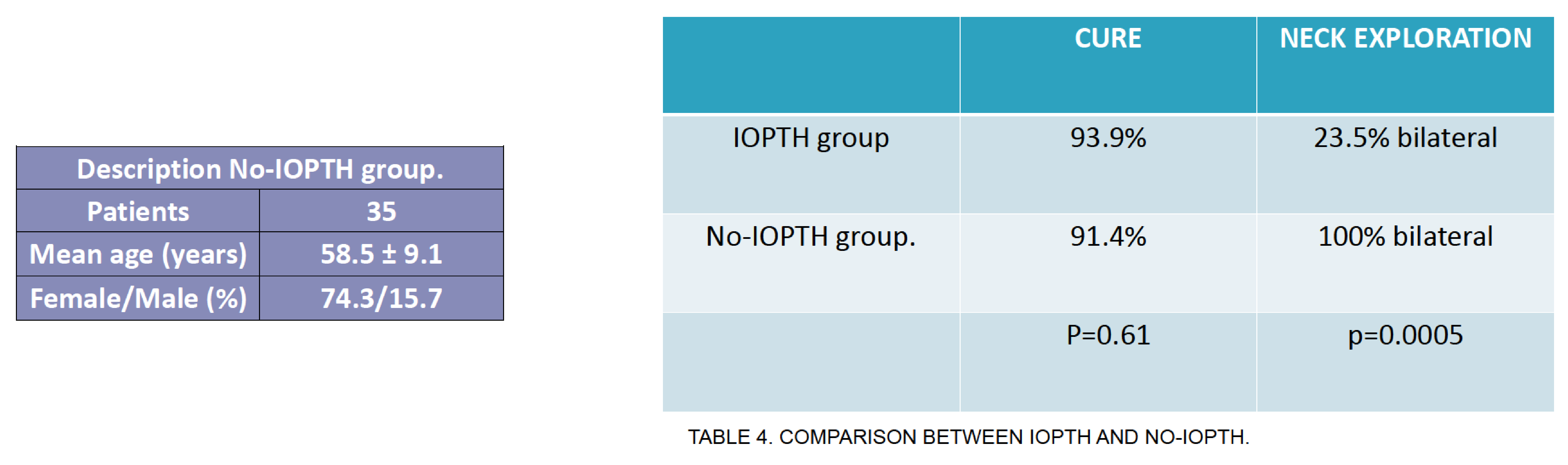

\section{CONCLUSION}

* By monitoring IOPTH in focused parathyroidectomy it is possible to perform a less invasive surgical approach without reduction in cure rate. 